\title{
Effet du stade de maturité du Medicago sativa et du Lolium multiflorum sur les dégradabilités des parois cellulaires (NDF) et de la matière organique (MO) dans le rumen mesurées in vivo *
}

\author{
G Piva, F Masoero, R Riccardi
}

Istituto Scienze della Nutrizione, Facolta Agraria UCSC, Via E Parmense, 84, 29100 Piacenza, Italie

\begin{abstract}
Summary - Effect of stage of maturity of lucerne and Italian ryegrass on the degradability of cell walls and organic matter in the rumen, measured in vivo. Lucerne and Italian ryegrass at 3 stages of maturity were evaluated in vivo by the nylon bag technique for NDF and OM rumen degradability rate. Rye-grass NDF content and NDF degradability were higher $(P<0.01)$ with respect to alfalfa at all maturity stages. ADF contents were near equal. It was concluded that the method of calculation proposed for net energy values from ADF content with corrections for NDF content was inadequate for the 2 families of forages at all stages of maturity.
\end{abstract}

Les travaux récents de Burton (1990) ont montré que la vitesse de dégradation ruminale des parois cellulaires (NDF) varie avec le stade végétatif mais de façon différente chez les Légumineuses et chez les Graminées. Antérieurement Smith et al (1972) avaient observé que les proportions entre hémicellulose et lignine diffèrent dans les 2 familles. Par ailleurs, les Légumineuses à plus forte teneur en lignine que les Graminées ont une dégradabilité totale de la matière sèche dans le rumen plus faible, tout en ayant une vitesse de dégradation des parois cellulaires plus élevée.

Ces différences de comportement entre Graminées et Légumineuses doivent avoir des répercussions sur l'estimation de leur valeur énergétique à partir des teneurs en parois cellulaires (NDF) et en lignocellulaose (ADF), notamment selon leur stade de développement. L'objet de cette étude est de comparer la cinétique de dégradation dans le rumen des parois cellulaires (et de la matière organique) de Medicago sativa et de Lolium multiflorum (ray-grass d'Italie) à 3 stades de maturité.

Matériel et méthodes - Trois génisses porteuses d'une fistule du rumen reçoivent $13,2 \mathrm{~kg}$ de matières sèches (MS) (2,3 fois le niveau d'entretien) d'une ration à $14 \%$ de matières azotées (\% MS) constituée d'ensilage de maïs, de foin de luzerne et d'aliments concentrés dans le rapport 28-35-37, distribuée en 2 fois par jour à $8 \mathrm{~h}$ et $17 \mathrm{~h}$. Deux variétés de luzerne (Romagnola et Marchigiana) et 2 variétés de ray-grass d'Italie récoltées à 3 stades de maturité ont été utilisées pour la mesure de la dégradabilité in sacco dans le rumen. Les conditions de cette mesure ont été les suivantes : broyage à travers une grille à maille de $1 \mathrm{~mm}$, sachets de nylon $(10 \times 15 \mathrm{~cm})$ ayant un diamètre des pores de $40 \mu$, durées d'incubation de $0,4,8,16,24,48$, $72 \mathrm{~h}$, mesures en quadruple.

Résultats et discussion - Les analyses chimiques montrent de grandes différences entre luzernes et ray-grass dans les teneurs en NDF et ADF (tableau I). À même stade de maturité, le ray-grass et la

\footnotetext{
* Travail subventionné par le ministère de l'Agriculture et de la Forêt. Projet «Moderne strategie lattiero-casearie".
} 
luzerne ont une dégradabilité de la matière organique presque équivalente alors que la dégradabilité de NDF est beaucoup plus élevée pour le ray-grass, quelle que soit la durée d'incubation.

La détermination de la teneur en énergie nette (NEL) d'après celle en ADF conduirait à des valeurs semblables pour le ray-grass et la luzerne à chacun des 3 stades mais l'application des corrections proposées par Mertens (1983) en fonction de la teneur en NDF conduirait à réduire les valeurs énergétiques du ray-grass. Or, en fait, la dégradabilité plus élevée de la fraction NDF du ray-grass devrait conduire à une fourniture d'énergie plus importante, même si sa teneur en NDF est plus éle- vée. II semble donc que les corrections proposées en fonction de la teneur en NDF pour le calcul de la valeur énergétique nette des fourrages ne peuvent pas être utilisées de façon uniforme, quel que soit le stade de maturité du fourrage, et qu'elles peuvent conduire à des valeurs erronées, notamment pour les jeunes fourrages à faible teneur en $\operatorname{ADF}(<33 \%)$ du fait de la structure et de la composition particulières de leurs parois cellulaires.
Buxton DR (1990) US Dairy Research Center, 1989 Research Summaries, 19-22
Mertens DR (1983) Cornell Nutrition Confe- rence, $60-68$
Smith LW, Goering HK, Gordon CH (1972) J Dainy Sci 55 (8), 1141-1147

Tableau I. Teneurs et dégradabilités comparées des constituants pariétaux de la luzerne (Luz) et du ray-grass d'Italie (RG).

\begin{tabular}{|c|c|c|c|c|c|}
\hline \multirow[t]{2}{*}{ Stade } & & \multicolumn{2}{|c|}{ Pourcentage matière sèche } & \multicolumn{2}{|c|}{ Degradabilité (\%) $(48 h)$} \\
\hline & & $A D F$ & $N D F$ & $A D F$ & NDF \\
\hline 1 & $\begin{array}{l}\text { Luz } \\
\text { RG }\end{array}$ & $\begin{array}{l}17,5 \\
19,9\end{array}$ & $\begin{array}{l}25,7 \\
40,9\end{array}$ & $\begin{array}{l}69,5 \\
88,0\end{array}$ & $\begin{array}{l}85,6 \\
90,6\end{array}$ \\
\hline 2 & $\begin{array}{l}\text { Luz } \\
\text { RG }\end{array}$ & $\begin{array}{l}26,5 \\
25,3\end{array}$ & $\begin{array}{l}36,1 \\
47,3\end{array}$ & $\begin{array}{l}57,1 \\
79,4\end{array}$ & $\begin{array}{l}78,2 \\
85,7\end{array}$ \\
\hline 3 & $\begin{array}{l}\text { Luz } \\
\text { RG }\end{array}$ & $\begin{array}{l}33,6 \\
32,0\end{array}$ & $\begin{array}{l}44,3 \\
56,3\end{array}$ & $\begin{array}{l}48,1 \\
56,5\end{array}$ & $\begin{array}{l}68,3 \\
69,4\end{array}$ \\
\hline
\end{tabular}
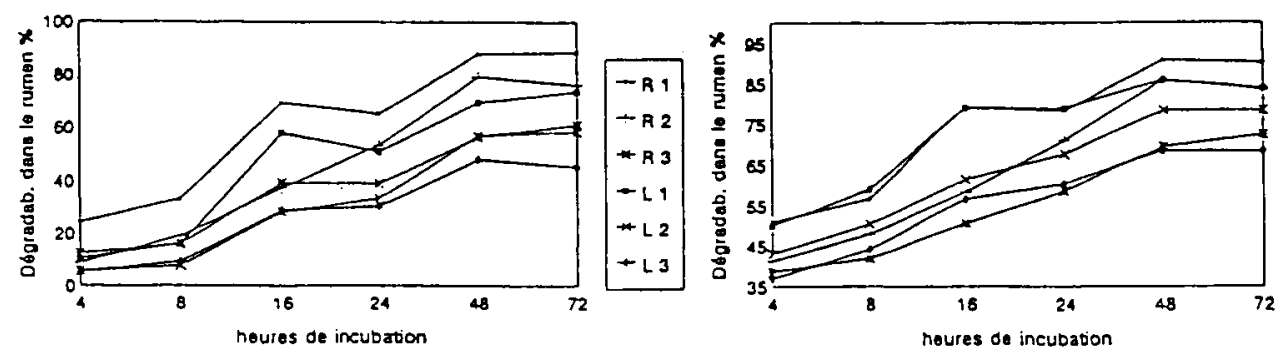

Fig 1. Cinétiques de dégradation dans le rumen de la luzerne $(L)$ et de ray-grass $(R)$ à 3 stades de maturité $(1,2,3)$. 